\title{
Composição Química e Digestibilidade da Massa de Forragem em Pastagem Irrigada de Capim-Aruana Exclusivo ou Sobre-Semeado com Mistura de Aveia Preta e Azevém ${ }^{1}$
}

\author{
Luciana Gerdes 2 , Herbert Barbosa de Mattos 3 , Joaquim Carlos Werner ${ }^{4}$, Maria Tereza \\ Colozza ${ }^{4}$, Eduardo Antonio da Cunha ${ }^{4}$, Mauro Sartori Bueno ${ }^{4}$, Rosana Aparecida Possenti ${ }^{4}$, \\ Eliana Aparecida Schammass ${ }^{4}$
}

\begin{abstract}
RESUMO - Uma mistura de duas espécies forrageiras de inverno: aveia preta (Avena strigosa Schreb cv. Comum) e azevém anual (Lolium multiflorum Lam. cv. Comum) foi sobre-semeada em uma pastagem de capim-aruana (Panicum maximum Jacq. cv. Aruana), utilizada com ovinos em sistema intensivo de produção (irrigação, adubação e lotação rotacionada), com o objetivo de melhorar o valor nutritivo da forragem no período crítico do ano. Nos doi anos (primeiro ano: 14/04/00 a 18/01/01 e segundo ano: 07/06/01 a 22/02/02), foram avaliadas a composição química e digestibilidade da forragem, antes da entrada dos animais (pré-pastejo) nas pastagens, em seis períodos de pastejo. O delineamento experimental foi de blocos completos casualizados (quatro), com duas repetições dentro do bloco e dois tratamentos: 1) capim-aruana exclusivo e 2) capim-aruana sobre-semeado. Para as amostras do total da forragem pré-pastejo e dos componentes (aruana, aveia preta e azevém), avaliaram-se os teores de proteína bruta (PB), de fibra em detergente neutro (FDN), de fibra em detergente ácido (FDA) e de lignina e a digestibilidade in vitro da matéria seca. No primeiro ano, a PB da forragem de capim-aruana exclusivo foi maior que a do sobre-semeado no terceiro período de pastejo e semelhante nos demais. FDN, FDA e lignina da forragem no tratamento exclusivo foram mais elevadas que no tratamento sobre-semeado, na média dos seis períodos. A digestibilidade da forragem foi semelhante nos dois tratamentos, em todos os períodos de avaliação. No segundo ano, o teor de PB da massa total de forragem da pastagem de capim-aruana exclusivo foi maior que o da pastagem sobre-semeada, no quarto período, porém semelhante nos demais e na média dos seis períodos. Os teores de FDN, FDA e lignina e a DIVMS da massa total de forragem foram semelhantes nas duas pastagens na média e ao longo dos seis períodos, exceto para FDN no segundo período. Pastos com capim-aruana sob adubação nitrogenada, irrigação e manejo adequados apresentaram composição química e digestibilidade semelhantes às de pastos do capim sobre-semeados com aveia preta e azevém.
\end{abstract}

Palavras-chave: digestibilidade in vitro da matéria seca, fibra em detergente ácido, fibra em detergente neutro, forrageira de inverno, proteína bruta

\section{Chemical Composition and Digestibility of Forage Mass in Irrigated Aruanagrass Pastures or Oversown with a Mixture of Winter Forage Species}

\begin{abstract}
A mixture of two winter forages: black oat (Avena strigosa Schreb. cv. Common) and Italian ryegrass (Lolium multiflorum Lam. cv. Common) was introduced in a pasture of aruanagrass (Panicum maximum Jacq. cv. Aruana), grazed by sheep in an intensive production system (irrigation, fertilization and rotational stocking) with the objective of increasing the forage nutritive value during the dry winter period. From 04-14-00 to 01-18-01 and 06-07-01 to 02-22-02, the chemical composition and digestibility of pregrazing forage were evaluated in six grazing periods. A completely randomized block design with replication within blocks was used. The treatments were 1) grass alone and 2) the grass oversown with the mixture of winter forages. Samples of pre-grazing forage mass and components (aruanagrass, black oat and Italian ryegrass) were taken to evaluate the forage botanical composition, contents of crude protein (CP), neutral detergent fiber (NDF), acid detergent fiber (ADF) and lignin and in vitro dry matter digestibility (IVDMD), in the six grazing periods. In the first year, the control had a greater CP content than oversown pasture in the third period and similar in the others periods, as well as greater NDF, ADF and lignin contents in the overall mean of the six grazing periods. Forage IVDMD from the two treatments were similar in all grazing periods. In the second year,the control had a greater CP content than oversown pasture in the fourth period and similar in the others periods, as well as greater NDF, ADF, lignin and IVDMD contents in the overall mean of the six grazing periods. Nitrogen fertilized and irrigated aruanagrass pastures and aruanagrass pastures oversown with black oat and Italian ryegrass exhibited the same values of chemical composition and digestibility.
\end{abstract}

Key Words: in vitro dry matter digestibility, acid detergent fiber, crude protein, neutral detergent fiber, winter forages

\footnotetext{
1 Parte da tese de Doutorado da primeira autora. Projeto financiado pelo Instituto de Zootecnia e pela FAPESP.

${ }^{2}$ Pesquisadora da Apta Regional - Pólo Regional do Sudoeste Paulista. Estação experimental de Itapetininga, SP. E.mail: lucianagerdes@yahoo.com.br

3 Orientador da primeira autora junto ao curso em Ciência Animal e Pastagens, ESALQ/USP.

4 Pesquisador do Instituto de Zootecnia, Cx.P 60, CEP 13460-00, Nova Odessa/SP.
} 


\section{Introdução}

A produção animal em pastagem acompanha os ciclos de crescimento das plantas forrageiras, que estão relacionados às chuvas e à temperatura. Entretanto, independentemente do método de pastejo empregado, procura-se sempre obter, economicamente, máxima produção de forragem de boa qualidade, com distribuição regular durante o ano.

A prática da introdução de espécies forrageiras de ciclo hibernal em pastagens tropicais resulta em melhor distribuição da produção de forragem ao longo do ano, bem como em aumento na proteína bruta e digestibilidade da forragem durante o período crítico (Reis et al., 1993, 2001).

Entre as gramíneas tropicais, os cultivares de Panicum maximum normalmente apresentam qualidade de média a boa (Euclides et al., 1996). O capimaruana tem se destacado por apresentar melhor distribuição anual de produção (Cecato et al., 1994; Ghisi et al., 1989) associado a razoável valor nutritivo durante o período crítico no ano (Ghisi et al., 1989).

As razões do bom desempenho animal em pastagens contendo a mistura de espécies forrageiras de inverno estão na qualidade de foragem e que varia conforme o estádio do desenvolvimento (Floss, 1988).

Restle et al. (2000) semearam a mistura de aveia preta e azevém sobre a palhada do milheto (Pennisetum americanum (L) Leeke) e obtiveram médias de $22,4 \%$ de PB e 57,4\% de DIVMO, no Sul do país.

Neste trabalho, objetivou-se avaliar, durante seis períodos de pastejo, a composição química e a digestibilidade da forragem de uma pastagem de Panicum maximum Jacq. cv. Aruana, irrigada, adubada e manejada em lotação rotacionada com ovinos, na qual foi sobre-semeada uma mistura de duas espécies forrageiras de inverno.

\section{Material e Métodos}

O experimento foi conduzido na unidade de ovinos e nos laboratórios do Instituto de Zootecnia, em Nova Odessa, São Paulo. Aproveitou-se um piquete de capim-aruana (Panicum maximum Jacq. cv. Aruana) com, aproximadamente $3.000 \mathrm{~m}^{2}$, estabelecido, em 1991, em um solo classificado como Argissolo Vermelho-Amarelo.

Foram avaliadas a composição química e a digestibilidade da massa de forragem antes da entrada dos animais na pastagem composta da mistura de duas espécies forrageiras de inverno: aveia preta (Avena strigosa Schreb cv. Comum) e azevém (Lolium multiflorum Lam. cv. Comum) introduzidas em uma pastagem de capim-aruana, pastejada em lotação intermitente com ovinos.

O delineamento experimental foi o de blocos completos casualizados (quatro) com duas repetições por bloco. Os tratamentos foram: 1) capim-aruana exclusivo e 2) capim-aruana sobre-semeado com a mistura das duas espécies forrageiras de inverno, totalizando 16 parcelas experimentais de $100 \mathrm{~m}^{2}$ cada.

Para a introdução da mistura das duas forrageiras de inverno, foi feito o rebaixamento prévio de todas as parcelas experimentais com pastejo (ovinos), obtendo-se altura do dossel em torno de $5 \mathrm{~cm}$. A semeadura, em cobertura e a lanço, sem enterrio das sementes, ocorreu em 14 de abril/2000, no primeiro ano e em 07 de junho/2001, no segundo ano, misturando-se as sementes $\left(65 \mathrm{~kg} \mathrm{ha}^{-1}\right.$ de aveia preta, $30 \mathrm{~kg} \mathrm{ha}^{-1}$ de azevém) com os adubos ( $40 \mathrm{~kg} \mathrm{ha}^{-1}$ de $\mathrm{P}_{2} \mathrm{O}_{5}, 42 \mathrm{~kg} \mathrm{ha}^{-1}$ de $\mathrm{K}_{2} \mathrm{O}$ e $30 \mathrm{~kg} \mathrm{ha}^{-1}$ de FTE BR-16).

Em novembro/2000, foi realizada a adubação nitrogenada $\left(50 \mathrm{~kg} \mathrm{ha}^{-1}\right.$ de $\left.\mathrm{N}\right)$ e potássica $\left(50 \mathrm{~kg} \mathrm{ha}^{-1}\right.$ de $\mathrm{K}_{2} \mathrm{O}$ ) nas parcelas experimentais. Em março/ 2001, foi realizada a adubação nitrogenada do final do período das águas, aplicando-se $100 \mathrm{~kg}_{\text {de }} \mathrm{kg} \mathrm{ha}^{-1} \mathrm{e}$, em meados de outubro/2001, início do período das águas, aplicaram-se $50 \mathrm{~kg} \mathrm{ha}^{-1} \mathrm{de} \mathrm{N}$.

A área foi dividida em faixas, delimitadas por cerca elétrica no momento do pastejo, sendo que cada bloco era constituído por uma faixa, pastejada em sequência, por dois a três dias, pelo mesmo lote de ovinos, simultaneamente nas parcelas do capimaruana exclusivo (testemunha) e nas da mistura das espécies forrageiras de inverno introduzidas sobre o capim. No primeiro ano experimental (14/04/00 a 18/01/01) ocorreram seis períodos de pastejo (P): P1: 24/05 a 01/06/00, P2: 04/07 a 12/07/00, P3: 30/08 a 05/09/00, P4: 18/10 a 26/10/00, P5: 06/12 a 20/12/00 e P6: 09/01 a 18/01/01 precedidos de seis períodos de descanso, com aproximadamente 40, 39, 55, 47, 46 e 32 dias, respectivamente. No segundo ano experimental (07/06/01 a 22/02/02), também houve seis períodos de pastejo (P): P1: 27/07 a 06/08/01, P2: 06/ 09 a 16/09/01, P3: 22/10 a 02/11/01, P4: 26/11 a $11 /$ 12/01, P5: 02/01 a 14/01/02 e P6: 06/02 a 22/02/02 e seis períodos de descanso, em torno de 50, 39, 43, 32 , 34 e 30 dias, respectivamente. 
As amostragens foram feitas em quatro locais por parcela $\left(100 \mathrm{~m}^{2}\right)$, antes da entrada dos animais, por meio do lançamento ao acaso de um quadrado de $0,25 \mathrm{~m}^{2}$, perfazendo um total de $1 \mathrm{~m}^{2}$. O corte era rente ao solo, com tesoura de poda. A forragem proveniente dessa amostra foi pesada, retirando-se $200 \mathrm{~g}$ para obtenção da subamostra do total de forragem prépastejo; o restante foi separado nos componentes botânicos capim-aruana, plantas invasoras, material morto, aveia preta e azevém, que foram novamente pesados, amostrados e secados em estufa de circulação forçada de ar $\left(65^{\circ} \mathrm{C}\right)$, até peso constante.

Tanto nas amostras da massa total de forragem, quanto nas dos componentes forrageiros (aruana, aveia preta e azevém), após passarem pelo processo de moagem em moinho tipo Willey com peneira de 40 mesh, foram determinadas: porcentagem de matéria seca $\left(105^{\circ} \mathrm{C}\right)$, proteína bruta $(\mathrm{PB})$, fibra insolúvel em detergente neutro(FDN), fibra insolúvel em detergente ácido (FDA), lignina e digestibilidade in vitro da matéria seca (DIVMS).

As determinações do teor de matéria seca a $105^{\circ} \mathrm{C}$ foram realizadas segundo Silva (1981). A digestão utilizada para obtenção do ex trato na determinação do nitrogênio total foi a sulfúrica, com destilação conduzida em aparelho semi-micro Kjeldahl, titulando-se posteriormente com ácido sulfúrico (AOAC, 1995).

Para o constituinte fibra (FDN, FDA e lignina) as determinações foram realizadas pelo método de Goering \& Van Soest (1970) e a DIVMS pelo método proposto por Tilley \& Terry (1963).

Os dados foram analisados pelos procedimentos MIXED e medidas repetidas no tempo (Repeated Measures) (Littell et al., 1996), do programa SAS ${ }^{\circledR}$ (SAS, 1990), a fim de se determinar a estrutura da matriz de variância e covariância. O nível de significância adotado para a análise de variância foi de $10 \%$. Para os efeitos significativos, foram realizados testes de comparação de médias, pelo procedimento LSMEANS, com nível de significância de 10\%. As interações significativas foram desdobradas de acordo com os fatores envolvidos.

\section{Resultados e Discussão}

Na Tabela 1, são apresentados os teores de PB da massa total de forragem e dos seus componentes (aruana, aveia preta e azevém), em seis períodos de pastejo com ovinos.
A interação períodos de pastejo $\mathrm{x}$ tipos de pastagem para os teores de PB da massa total de forragem (Tabela 1) foi significativa $(P=0,0977)$. Apenas no terceiro período de pastejo (P3: 30/08 a 05/09/00), o teor de PB da massa total de forragem diferiu entre os dois tipos de pastagem, sendo maior na pastagem de capim-aruana exclusivo $(P=0,0033)$. Neste período, houve também boa contribuição da aveia preta e do azevém $\left(0,73\right.$ t. MS ha $\left.{ }^{-1}\right)$ no tratamento sobresemeado (Gerdes et al., 2005). Porém, os teores de PB das forrageiras de inverno foram menores em relação aos do capim-aruana (Tabela 1), por estarem em estádio avançado de desenvolvimento e com as menores porcentagens de lâminas (Gerdes et al., 2005), fazendo baixar os teores de PB do tratamento sobre-semeado. Este fato não ocorreu nos dois primeiros períodos de pastejo (P1:24/05 a 01/06/00 e P2: 04/07 a 12/07/00), quando os teores de PB da aveia e do azevém foram mais elevados $(P=0,0001)$ que os do terceiro e, especialmente do quarto período (P4: 18/10 a 26/10/00) para o azevém, que caiu a 9,0\%. Restle et al. (2000), contrariamente verificaram os menores teores de $\mathrm{PB}$ da forragem em pastagens de aveia preta + azevém no primeiro (02/06 a 02/07) e segundo (02/07 a 05/08) períodos de pastejo e o maior no terceiro $(05 / 08$ a $25 / 08)$.

Os teores de $\mathrm{PB}$ do componente aruana foram semelhantes $(P=0,4115)$ entre as duas pastagens em todos os períodos de avaliação e nas suas médias (Tabela 1), sendo superiores aos encontrados por Ghisi et al. (1989) e Cecato et al. (1994). Zimmer (1999), trabalhando com duas alturas pós-pastejo e duas doses de nitrogênio em capim-aruana, na estação seca do ano, obteve teor médio de proteína bruta de $18,7 \%$. Esse valor foi próximo aos do componente aruana mostrados na Tabela 1 , nos períodos referentes à estação seca do ano (P1, P2 e P3).

Nas Tabelas 2 e 3, encontram-se os dados referentes aos conteúdos de FDN, FDA e lignina da massa total de forragem ofertada para os animais e dos componentes forrageiros nas pastagens sobresemeada e exclusiva de capim-aruana, em seis períodos de utilização.

Os teores de FDN da massa total de forragem na pastagem sobre-semeada foram menores $(\mathrm{P}<0,10)$ que os da pastagem exclusiva de capim-aruana, tanto na média dos períodos de pastejo $(P=0,0127)$ quanto nos dois primeiros ( $\mathrm{P} 1: P=0,0682$ e $\mathrm{P} 2: P=0,0145)$, permanecendo semelhantes $(\mathrm{P}>0,10)$ nos demais períodos de utilização das pastagens (Tabela 2). Os 
Tabela 1 - Teores de proteína bruta da massa de forragem e dos componentes forrageiros em pastagens de capimaruana exclusivo (AE) e capim-aruana sobre-semeado com uma mistura de espécies forrageiras de inverno $(\mathrm{MFI})$ antes da entrada dos ovinos em seis períodos de pastejo $(\mathrm{P})$ no primeiro ano de experimento

Table 1 - Contents of crude protein of pre-grazing forage mass and botanical composition in pure aruanagrass (PA) and aruanagrass oversown with a mixture of winter forages (MWF), in the six grazing periods of the first year

\begin{tabular}{|c|c|c|c|c|c|c|c|}
\hline \multirow[b]{2}{*}{$\begin{array}{l}\text { Tipo de pastagem } \\
\text { Pasture type }\end{array}$} & \multicolumn{6}{|c|}{$\begin{array}{l}\text { Período de pastejo } \\
\text { Grazing period }\end{array}$} & \multirow[b]{2}{*}{$\begin{array}{l}\text { Média* } \\
\text { Mean* }\end{array}$} \\
\hline & $\begin{array}{c}\mathrm{P} 1 \\
24 / 05 \mathrm{a} \\
01 / 06 / 00 \\
05-24 \text { to } \\
06-01-00\end{array}$ & $\begin{array}{c}\mathrm{P} 2 \\
04 / 07 \mathrm{a} \\
12 / 07 / 00 \\
07-04 \text { to } \\
07-12-00\end{array}$ & $\begin{array}{c}\mathrm{P} 3 \\
30 / 08 \mathrm{a} \\
05 / 09 / 00 \\
08-30 \text { to } \\
09-05-00\end{array}$ & $\begin{array}{c}\mathrm{P} 4 \\
18 / 10 \mathrm{a} \\
26 / 10 / 00 \\
10-18 \text { to } \\
10-26-00\end{array}$ & $\begin{array}{c}\text { P5 } \\
06 / 12 \mathrm{a} \\
20 / 12 / 00 \\
12-06 \text { to } \\
12-20-00\end{array}$ & $\begin{array}{c}\mathrm{P} 6 \\
09 / 01 \mathrm{a} \\
18 / 01 / 01 \\
01-09 \text { to } \\
01-18-01\end{array}$ & \\
\hline \multicolumn{8}{|c|}{ Total $(\%)$} \\
\hline $\begin{array}{l}\operatorname{MFI}(M W F) \\
\operatorname{AE}(P A)\end{array}$ & $\begin{array}{l}16,1^{\mathrm{a}} \\
16,5^{\mathrm{a}}\end{array}$ & $\begin{array}{l}17,0^{\mathrm{a}} \\
16,3^{\mathrm{a}}\end{array}$ & $\begin{array}{r}14,8^{\mathrm{b}} \\
16,8^{\mathrm{a}} \\
\text { Aru } \\
\text { Aruan }\end{array}$ & $\begin{array}{c}9,9^{\mathrm{a}} \\
10,0^{\mathrm{a}} \\
(\%) \\
\text { ss }(\%)\end{array}$ & $\begin{array}{l}11,8^{\mathrm{a}} \\
12,2^{\mathrm{a}}\end{array}$ & $\begin{array}{l}12,2^{\mathrm{a}} \\
12,2^{\mathrm{a}}\end{array}$ & $\begin{array}{l}13,6^{\mathrm{a}} \\
14,0^{\mathrm{a}}\end{array}$ \\
\hline $\begin{array}{l}\operatorname{MFI}(M W F) \\
\operatorname{AE}(P A)\end{array}$ & $\begin{array}{l}17,4^{\mathrm{a}} \\
17,4^{\mathrm{a}}\end{array}$ & $\begin{array}{l}18,6^{\mathrm{a}} \\
17,8^{\mathrm{a}}\end{array}$ & $\begin{array}{l}17,3^{\mathrm{a}} \\
18,1^{\mathrm{a}}\end{array}$ & $\begin{array}{c}9,6^{\mathrm{a}} \\
10,2^{\mathrm{a}}\end{array}$ & $\begin{array}{l}11,7^{\mathrm{a}} \\
12,6^{\mathrm{a}}\end{array}$ & $\begin{array}{l}12,7^{\mathrm{a}} \\
13,1^{\mathrm{a}}\end{array}$ & $\begin{array}{l}14,6^{\mathrm{a}} \\
14,9^{\mathrm{a}}\end{array}$ \\
\hline $\operatorname{MFI}(M W F)$ & $19,9^{\mathrm{A}}$ & $18,7^{\mathrm{A}}$ & $\begin{array}{r}\text { Avei } \\
\text { Blac } \\
14,2^{\mathrm{B}} \\
\text { Aze } \\
\text { Italian } \\
14,1^{\mathrm{B}}\end{array}$ & $\begin{array}{l}\operatorname{ta}(\%) \\
(\%) \\
(\%) \\
\operatorname{ass}(\%) \\
9,0^{C}\end{array}$ & - & - & 17,5 \\
\hline
\end{tabular}

* EPM: erro-padrão da média (standard error of mean). $\mathrm{EPM}_{\mathrm{MFI}, \mathrm{AE}-\mathrm{Total}}=0,1866 ; \mathrm{EPM}_{\mathrm{MFI}, \mathrm{AE}-\mathrm{Aruana}}=0,2617 ; \mathrm{EPM}_{\mathrm{MFI}-\mathrm{Aveia}}=0,3352$; $\mathrm{EPM}_{\text {MFI-Azevém }}=0,3909$.

ab Médias seguidas de mesmas letras minúsculas, nas colunas, para cada variável, não diferem $(P>0,10)$ entre si.

$A B$ Médias seguidas de mesmas letras maiúsculas, nas linhas, não diferem $(P>0,10)$ entre si.

ab Means followed by the same small letters, in the columns, for each variable, do not differ $(P>0.10)$.

$A B$ Means followed by the same capital letters, in the rows, do not differ $(P>0.10)$.

mais baixos teores de FDN das duas forrageiras de inverno (Tabela 3 ), nos dois primeiros períodos, quando suas presenças eram em torno de $7,5 \%$ no P1 e $11,5 \%$ no P2 (Gerdes et al., 2005), colaboraram para a queda no teor de FDN da pastagem sobre-semeada. Ainda mais que os componentes botânicos (aruana, plantas invasoras e material morto) constituintes desta pastagem, tiveram presenças semelhantes quando comparados com os componentes da pastagem exclusiva (Gerdes et al., 2005), não interferindo, possivelmente, nos teores de FDN.

Os teores de FDA e lignina da massa total de forragem (Tabela 2) também foram menores $\left(P_{F D A}=\right.$ $\left(0,0123\right.$ e $P_{\text {Lignina }}=(0,0147)$ na pastagem contendo as forrageiras de inverno que na pastagem exclusiva, na média dos seis períodos de pastejo.

No componente aruana (Tabela 3), houve interação $(P=0,0548)$ entre períodos de pastejo e tipos de pastagem para FDN. No quarto período, o teor de FDN do aruana na pastagem exclusiva foi maior ( $P=0,0081)$ que o da pastagem sobre-semeada, não havendo diferença significativa entre os dois tipos de pastagem $(P=0,1305)$ nos demais e na média dos seis períodos, que apresentou 72,7 e 71,6\% para pastagem AE e MFI, respectivamente.

Para os teores de FDA e lignina do componente aruana (Tabela 3), não houve diferença significativa entre os dois tipos de pastagem $\left(P_{F D A}=0,1162 \mathrm{e}\right.$ $P_{\text {Lignina }}=(0,8053)$, na média dos seis períodos.

O teor de FDN da aveia preta (Tabela 3 ) aumentou de forma significativa $(P=0,001)$ com o avanço nos períodos de utilização da pastagem (P1: 56,5\%; P2: 60,2\% e P3: 65,8\%). Diferentemente, os teores de FDA e lignina, onde o FDA foi mais baixo $(\mathrm{P}<0,10)$ no último período (P3), mantiveram teores semelhantes ao longo desses três períodos avaliados.

$\mathrm{O}$ azevém apresentou aumento $(\mathrm{P}=0,0001)$ dos teores de FDN e FDA (Tabela 3) no período final (P4) do seu ciclo de crescimento, em relação aos precedentes. Segundo Blaser (1964), com a maturação, há acelerado acúmulo de carboidratos estruturais na parede celular de plantas forrageiras.

Os valores de digestibilidade in vitro da massa seca total de forragem e de seus componentes nas pastagens exclusivas e sobre-semeadas, ao longo dos seis períodos de utilização, são mostrados na Tabela 4. 
Tabela 2 - Teores de fibra em detergente neutro, fibra em detergente ácido e lignina da massa de forragem em pastagens de capim-aruana exclusivo (AE) e capim-aruana sobre-semeado com uma mistura de espécies forrageiras de inverno (MFI) antes da entrada dos ovinos em seis períodos de pastejo ( $\mathrm{P}$ ) no primeiro ano de experimento

Table 2 - Contents of neutral detergent fiber, acid detergent fiber and lignin of the pre-grazing forage mass in pure aruanagrass (PA) and aruanagrass oversown with a mixture of winter forages (MWF), in the six grazing periods of the first year

\begin{tabular}{|c|c|c|c|c|c|c|c|}
\hline \multirow{6}{*}{$\begin{array}{l}\text { Tipo de pastagem } \\
\text { Pasture type }\end{array}$} & \multicolumn{6}{|c|}{$\begin{array}{l}\text { Período de pastejo } \\
\text { Grazing period }\end{array}$} & \multirow[b]{2}{*}{ Média* } \\
\hline & P1 & $\mathrm{P} 2$ & P3 & P4 & P5 & P6 & \\
\hline & $24 / 05 \mathrm{a}$ & 04/07 a & $30 / 08 \mathrm{a}$ & $18 / 10 \mathrm{a}$ & $06 / 12 \mathrm{a}$ & 09/01 a & Mean* \\
\hline & 01/06/00 & $12 / 07 / 00$ & $05 / 09 / 00$ & $26 / 10 / 00$ & $20 / 12 / 00$ & $18 / 01 / 01$ & \\
\hline & $05-24$ to & $07-04$ to & $08-30$ to & $10-18$ to & $12-06$ to & $01-09$ to & \\
\hline & $06-01-00$ & $07-12-00$ & $09-05-00$ & $10-26-00$ & $12-20-00$ & $01-18-01$ & \\
\hline \multicolumn{8}{|c|}{ Fibra em detergente neutro (\%) } \\
\hline \multicolumn{8}{|c|}{ Neutral detergent fiber (\%) } \\
\hline MFI $(M W F)$ & $66,8^{\mathrm{b}}$ & $65,3^{\mathrm{b}}$ & $69,1^{\mathrm{a}}$ & $72,0^{\mathrm{a}}$ & $70,8^{\mathrm{a}}$ & $73,2^{a}$ & $69,5^{b}$ \\
\hline $\mathrm{AE}(P A)$ & $69,1^{\mathrm{a}}$ & $68,4^{\mathrm{a}}$ & $70,5^{\mathrm{a}}$ & $73,7^{\mathrm{a}}$ & $72,1^{\mathrm{a}}$ & $73,8^{\mathrm{a}}$ & $71,3^{\mathrm{a}}$ \\
\hline \multicolumn{8}{|c|}{ Fibra em detergente ácido (\%) } \\
\hline \multicolumn{8}{|c|}{ Acid detergent fiber (\%) } \\
\hline MFI $(M W F)$ & $35,6^{\mathrm{a}}$ & $34,0^{\mathrm{b}}$ & $34,9^{\mathrm{a}}$ & $38,8^{\mathrm{a}}$ & $38,6^{\mathrm{a}}$ & $43,3^{b}$ & $37,6^{\mathrm{b}}$ \\
\hline $\mathrm{AE}(P A)$ & $36,8^{a}$ & $36,3^{\mathrm{a}}$ & $36,7^{\mathrm{a}}$ & $37,8^{a}$ & $39,9^{a}$ & $46,1^{\mathrm{a}}$ & $38,9^{\mathrm{a}}$ \\
\hline \multicolumn{8}{|c|}{ Lignina $(\%)$} \\
\hline \multicolumn{8}{|c|}{ Lignin $(\%)$} \\
\hline MFI $(M W F)$ & $4,5^{\mathrm{a}}$ & $4,3^{\mathrm{a}}$ & $4,7^{\mathrm{b}}$ & $4,2^{\mathrm{a}}$ & $4,0^{\mathrm{a}}$ & $5,1^{\mathrm{a}}$ & $4,4^{b}$ \\
\hline $\mathrm{AE}(P A)$ & $4,8^{\mathrm{a}}$ & $4,7^{\mathrm{a}}$ & $5,4^{\mathrm{a}}$ & $4,1^{\mathrm{a}}$ & $4,0^{\mathrm{a}}$ & $5,4^{\mathrm{a}}$ & $4,9^{a}$ \\
\hline
\end{tabular}

Não houve diferença significativa entre os dois tipos de pastagem, na média dos seis períodos de pastejo, para a DIVMS da massa total de forragem $(P=0,4423)$ e da do componente aruana $(P=0,2903)$, que tiveram valores de 68,7 e $68,0 \%$ para a massa total de forragem e de 71,3 e 70,6\% para o componente aruana, nas pastagens de aruana com sobresemeadura e testemunha, respectivamente (Tabela 4). Esperava-se, de acordo com Reis et al. (1993), maior digestibilidade no tratamento do capim-aruana sobresemeado, o que, entretanto, não ocorreu, porque o aruana, tanto no tratamento exclusivo como no sobresemeado, apresentou elevadas porcentagens de digestibilidade (Tabela 4) e de proteína bruta (Tabela 1), em virtude das condições de adubação, irrigação e manejo utilizados, mostrando que, com estas práticas, a sobre-semeadura de forrageiras de inverno, seria desnecessária para melhorar o valor nutritivo de pastagens de capim-aruana.

Há forte relação entre proteína bruta e digestibilidade, quando determinadas em alimentos volumosos (Van Soest, 1982), como demonstraram resultados do presente trabalho, no capim-aruana.
A digestibilidade da aveia e do azevém decresceram $(P=0,0001)$ ao final dos seus ciclos de crescimento (Tabela 4). Os mais baixos teores de FDN e FDA do azevém (Tabela 3 ), nos três primeiros períodos (P1, P2 e P3), comparados com o P4, correspondem aos mais altos valores de DIVMS (Tabela 4). Esta relação inversa teor de FDN e digestibilidade também foi observada por Gomes \& Reis (1999), em forrageiras de inverno.

Os teores de proteína bruta da massa total de forragem e dos seus componentes forrageiros (aruana, aveia preta e azevém) das pastagens de capim-aruana exclusivo ou sobre-semeado, em seis períodos de pastejo com ovinos, estão apresentados na Tabela 5 .

Houve interação $(P=0,0260)$ entre períodos de pastejo e tipos de pastagem, quando se avaliou o teor de proteína bruta da massa total de forragem. No quarto período de pastejo (P4: 26/11 a 11/12/01), a massa total de forragem da pastagem exclusiva apresentou menor $(P=0,0024)$ teor de proteína bruta que a da pastagem sobre-semeada (Tabela 5). Nos demais períodos, os teores de PB foram semelhantes $(\mathrm{P}>0,10)$ entre os dois tratamentos, ocorrendo o mesmo 
Tabela 3 - Teores de fibra em detergente neutro, fibra em detergente ácido e lignina dos componentes forrageiros em pastagens de capim-aruana exclusivo $(A E)$ e capim-aruana sobre-semeado com uma mistura de espécies forrageiras de inverno (MFI) antes da entrada dos ovinos em seis períodos de pastejo (P) no primeiro ano de experimento

Table 3 - Contents of neutral detergent fiber, acid detergent fiber and lignin of the pre-grazing botanical composition in pure aruanagrass (PA) and aruanagrass oversown with a mixture of winter forages (MWF), in the six grazing periods of the first year

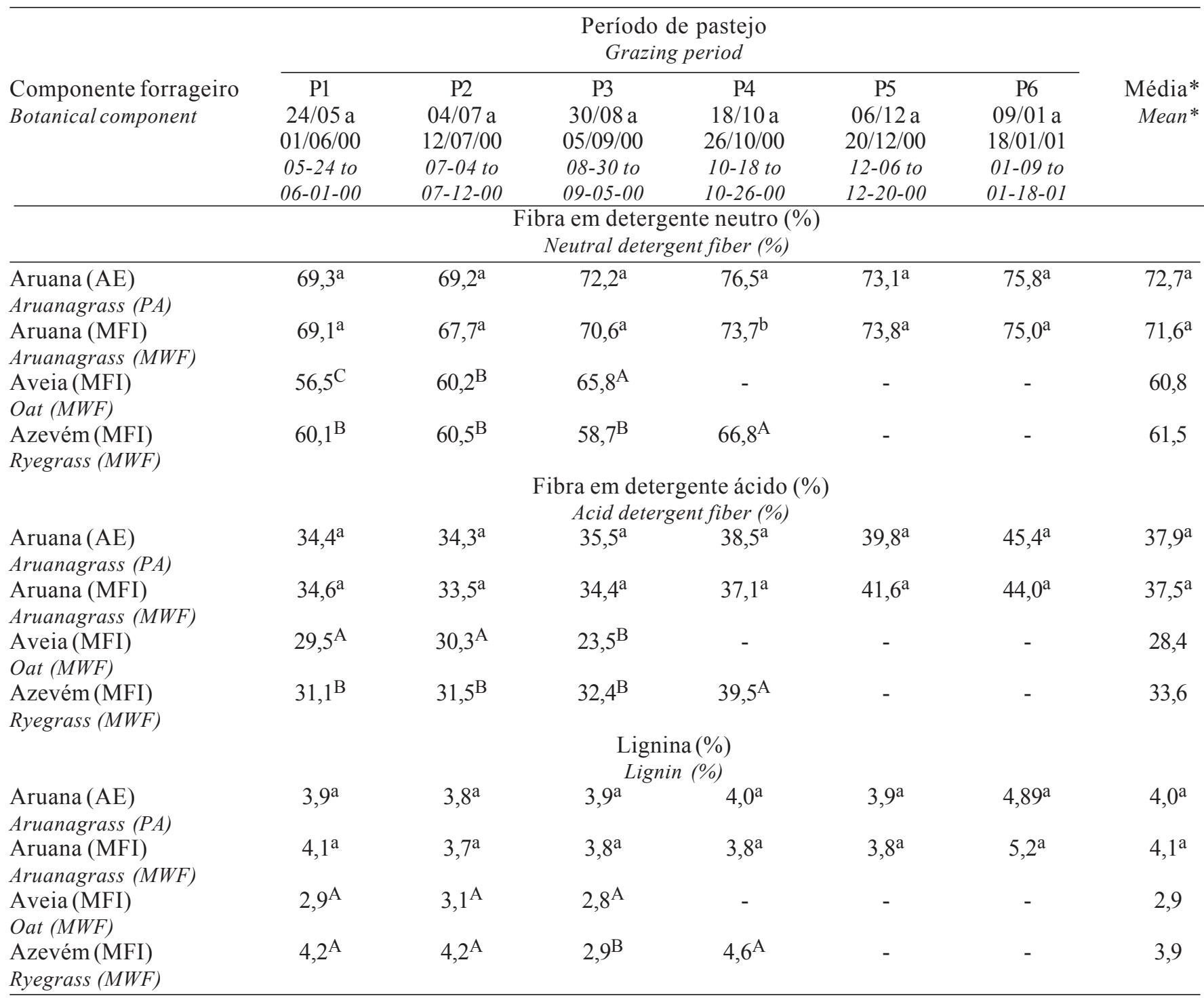

* EPM: erro-padrão da média (standard error of mean). $E_{P M} M_{M F I, A E-F D N(A r u a n a)}=0,4339 ; \quad E_{M P M} M_{M F D N(A v e i a)}=0,5374$; $\mathrm{EPM}_{\mathrm{MFI-FDN}(\text { Azevém) }}=0,4897 ; \mathrm{EPM}_{\mathrm{MFI}, \mathrm{AE}-\mathrm{FDA}(\text { Aruana) }}=0,1883 ; \mathrm{EPM}_{\mathrm{MFI-FDA}(\text { Aveia })}=0,5164 ; \mathrm{EPM}_{\mathrm{MFI-FDA}(\mathrm{Azevém})}=0,3030$; $\mathrm{EPM}_{\mathrm{MFI}, \mathrm{AE}-\text { Lig(Aruana) }}=0,0784 ; \mathrm{EPM}_{\mathrm{MFI} \text {-Lig(Aveia) }}=0,1028 ; \mathrm{EPM}_{\mathrm{MFI} \text {-Lig(Azevém) }}=0,1247$.

ab Médias seguidas de mesmas letras minúsculas, nas colunas, para cada variável, não diferem $(P>0,10)$ entre si.

$A B$ Médias seguidas de mesmas letras maiúsculas, nas linhas, não diferem entre si $(P>0,10)$.

ab Means followed by the same small letters, in the columns, for each variable, do not differ $(P>0.10)$.

$A B$ Means followed by the same capital letters, in the rows, do not differ $(P>0.10)$.

na média dos seis períodos $(P=0,7522), 13,3$ e 13,4\%, respectivamente, para MFI e AE.

Os teores de PB do componente aruana (Tabela 5), em todos os períodos de avaliação, assim como para a média, foram semelhantes $(P=0,8403)$ entre as duas pastagens. Os teores médios de PB, para ambas as alternativas de pastagem, foram superiores aos encontrados por Ghisi et al. (1989) e Cecato et al. (1994), em pastagem de capim-aruana.

Tanto para aveia preta quanto para azevém, os teores de PB decresceram com os períodos de pastejo (Tabela 5). Com o avanço dos estádios de maturação das espécies forrageiras de inverno, ocorre o acúmulo de carboidratos estruturais na parede celular das 
Tabela 4 - Digestibilidade in vitro da matéria seca da massa total de forragem e dos seus componentes forrageiros em pastagens de capim-aruana exclusivo (AE) e capim-aruana sobre-semeado com uma mistura de forrageiras de inverno (MFI) antes da entrada dos ovinos em seis períodos de pastejo $(\mathrm{P})$ no primeiro ano de experimento

Table 4 - In vitro dry matter digestibility of pre-grazing forage mass and botanical composition in pure aruanagrass (PA) and aruanagrass oversown with a mixture of winter forages (MWF), in the six grazing periods of the first year

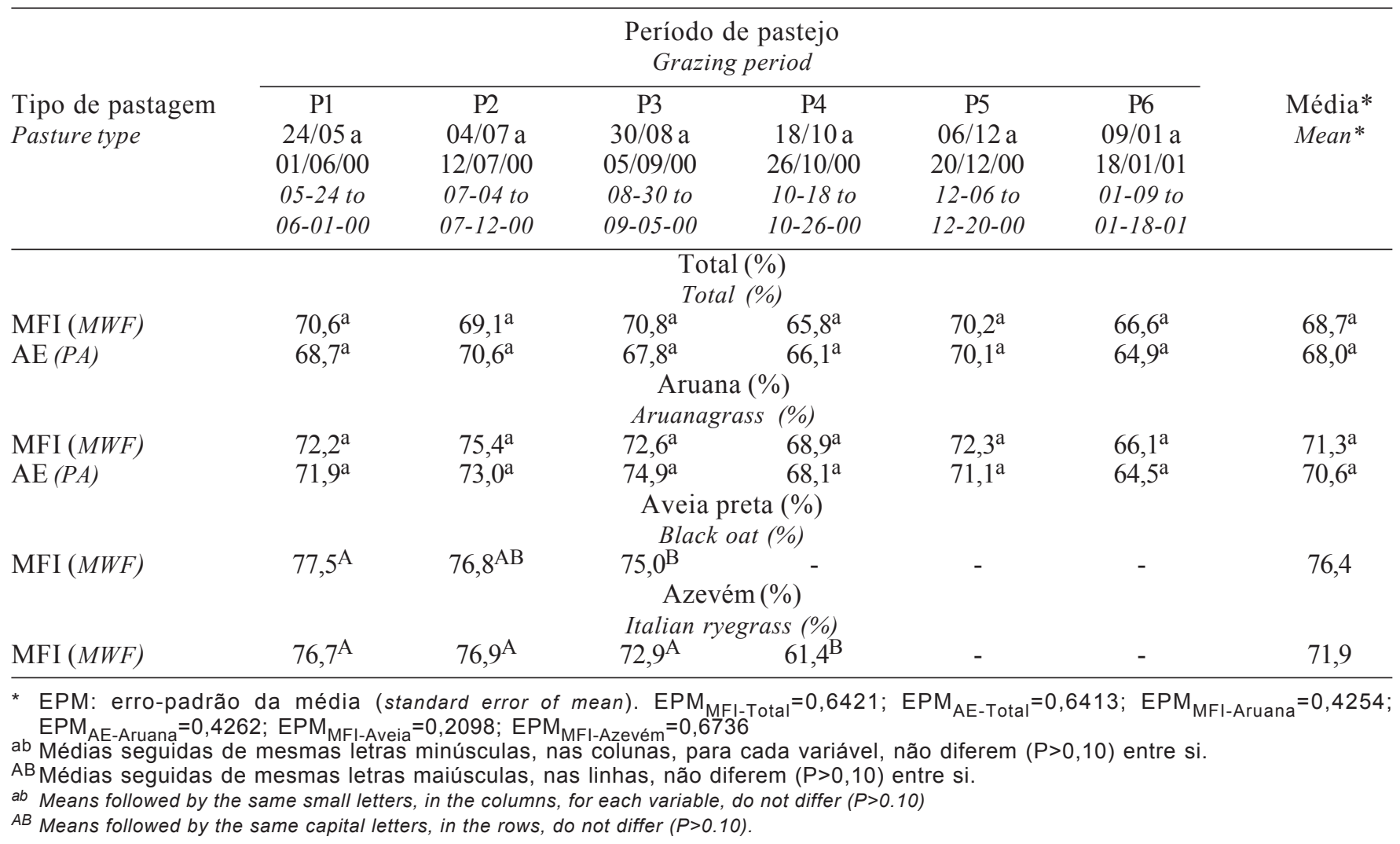

plantas forrageiras, diluição da concentração de nitrogênio e, conseqüentemente, diminuição do teor de proteína bruta, corroborando afirmações de Blaser(1964), Van Soest (1982), Floss (1988), Lupatini et al. (1998).

Na Tabela 6, encontram-se os teores de FDN, FDA e lignina da massa total de forragem nas pastagens sobre-semeadas e nas exclusivas, ao longo dos seis períodos de pastejo, que, na média dos períodos de utilização, foram semelhantes.

Constam da Tabela 7 os teores de FDN, FDA e lignina dos componentes forrageiros das pastagens, nos seis períodos de pastejo. Com exceção do FDA no componente aruana, que foi mais elevado $(P=0,0679)$, na pastagem contendo a mistura das forrageiras de inverno, na média dos períodos de avaliação. Para o aruana, os teores de FDN e de FDA foram semelhantes $(\mathrm{P}>0,10)$ entre as duas alternativas de pastagens, na média dos períodos de pastejo.

A aveia preta (Tabela 7) apresentou menores teores de FDN $(P=0,0007)$ e de lignina $(P=0,0421)$ no primeiro período de pastejo, que se elevaram no segundo período (final de seu ciclo vegetativo). Os teores de FDA da aveia foram semelhantes $(P=0,7350)$ entre os dois ciclos de pastejo. Essas características qualitativas, com exceção do teor de FDA, elevaram-se com a maturidade fisiológica da aveia (Gerdes et al., 2005).

Os menores teores de FDN e FDA do azevém ( $P=0,0001)$ foram encontrados no primeiro e segundo períodos e os maiores, no último período de pastejo (P3) (Tabela 7). No P3, o azevém apresentou a menor proporção de lâminas em relação às hastes (Gerdes et al., 2005), característica que afetou negativamente a qualidade desta planta. O azevém apresentou menor teor de lignina $(P=0,0001)$ na avaliação inicial (P1), com aumento acentuado na segunda e terceira avaliações (P2 e P3). Isto coincide com as observações de Blaser (1964) de que ocorre redução no valor nutritivo com o avanço da idade das plantas.

Lupatini et al. (1998), trabalhando com níveis de nitrogênio em aveia preta mais azevém em pastejo, de meados de julho até final de outubro, também encon- 
Tabela 5 - Teores de proteína bruta da massa total de forragem e dos seus componentes forrageiros em pastagens de capim-aruana exclusivo (AE) e capim-aruana sobre-semeado com uma mistura de espécies forrageiras de inverno $(\mathrm{MFI})$ antes da entrada dos ovinos em seis períodos de pastejo $(\mathrm{P})$ no segundo ano de experimento

Table 5 - Crude protein contents of pre-grazing forage mass and botanical composition in pure aruanagrass (PA) and aruanagrass oversown with a mixture of winter forages (MWF), in the six grazing periods of the second year

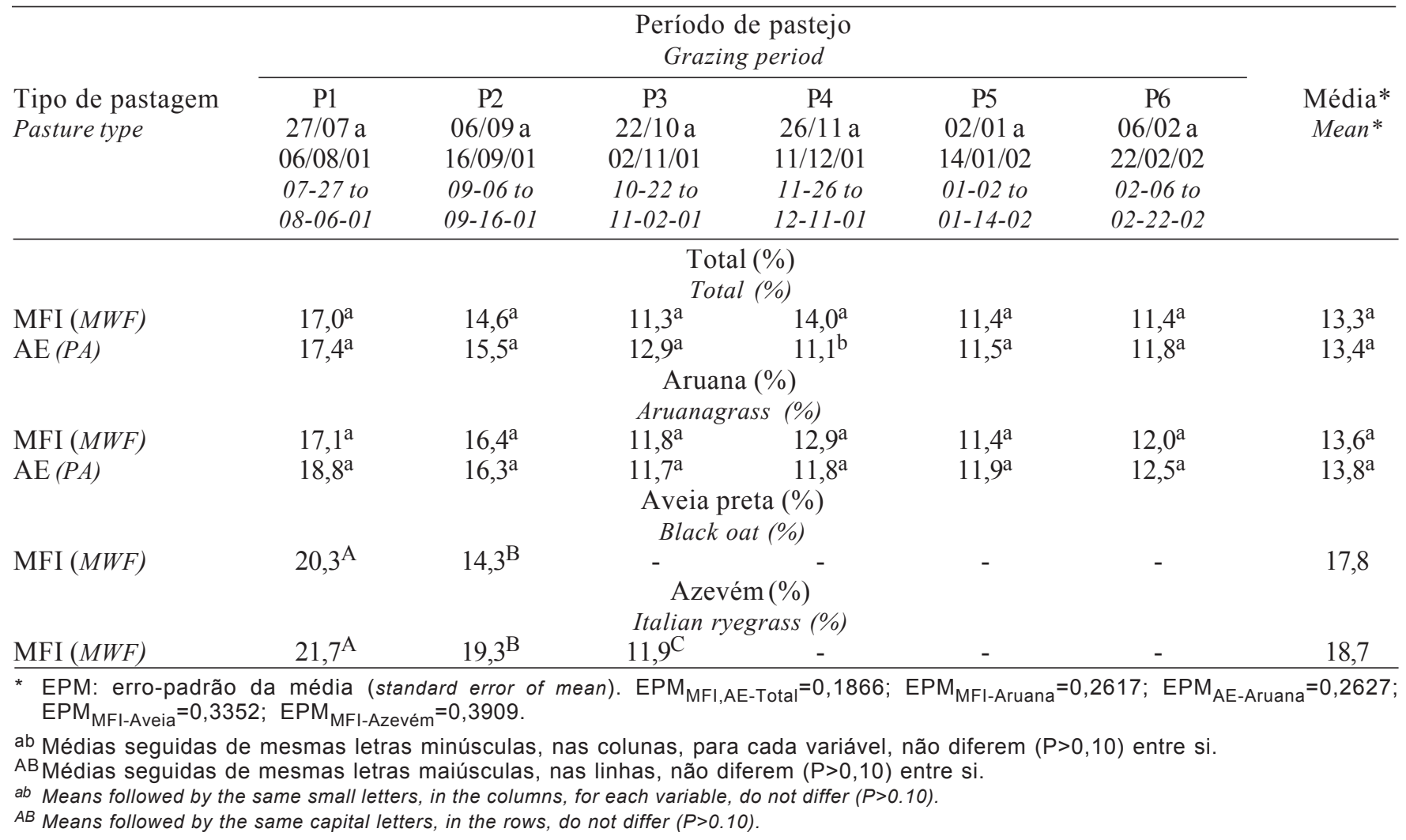

Tabela 6 - Teores de fibra em detergente neutro, fibra em detergente ácido e lignina da massa total de forragem em pastagens de capim-aruana exclusivo (AE) e capim-aruana sobre-semeado com uma mistura de espécies forrageiras de inverno (MFI) antes da entrada dos ovinos em seis períodos de pastejo (P) no segundo ano de experimento

Table 6 - Contents of neutral detergent fiber, acid detergent fiber and lignin of the pre-grazing forage mass in pure aruanagrass (PA) and aruanagrass oversown with a mixture of winter forages (MWF), in the six grazing periods of the second year

\begin{tabular}{|c|c|c|c|c|c|c|c|}
\hline \multirow{6}{*}{$\begin{array}{l}\text { Tipo de pastagem } \\
\text { Pastures type }\end{array}$} & \multicolumn{6}{|c|}{$\begin{array}{l}\text { Período de pastejo } \\
\text { Grazing period }\end{array}$} & \multirow[b]{2}{*}{ Média* } \\
\hline & P1 & P2 & P3 & P4 & P5 & P6 & \\
\hline & $27 / 07 \mathrm{a}$ & 06/09a & $22 / 10 a$ & $26 / 11 a$ & 02/01 a & $06 / 02 \mathrm{a}$ & Mean* \\
\hline & 06/08/01 & $16 / 09 / 01$ & $02 / 11 / 01$ & $11 / 12 / 01$ & $14 / 01 / 02$ & $22 / 02 / 02$ & \\
\hline & $07-27$ to & 09-06 to & $10-22$ to & $11-26$ to & $01-02$ to & $02-06$ to & \\
\hline & 08-06-01 & 09-16-01 & $11-02-01$ & $12-11-01$ & $01-14-02$ & $02-22-02$ & \\
\hline & & & ra em det & te neutro & & & \\
\hline & & & Neutral de & nt fiber $(\%$ & & & \\
\hline MFI $(M W F)$ & $64,7^{\mathrm{a}}$ & $65,7^{\mathrm{b}}$ & $71,4^{\mathrm{a}}$ & $70,7^{\mathrm{a}}$ & $72,8^{a}$ & $73,1^{\mathrm{a}}$ & $69,7^{\mathrm{a}}$ \\
\hline $\operatorname{AE}(P A)$ & $66,7^{\mathrm{a}}$ & $69,5^{\mathrm{a}}$ & $71,8^{\mathrm{a}}$ & $72,2^{\mathrm{a}}$ & $71,3^{\mathrm{a}}$ & $72,9^{\mathrm{a}}$ & 70,7 \\
\hline & & & pra em det & te ácido ( & & & \\
\hline & & & Acid deter & fiber (\%) & & & \\
\hline MFI $(M W F)$ & $34,3^{\mathrm{a}}$ & $34,2^{\mathrm{a}}$ & $39,0^{\mathrm{a}}$ & $38,8^{\mathrm{a}}$ & $43,7^{\mathrm{a}}$ & $42,4^{\mathrm{a}}$ & $38,7^{\mathrm{a}}$ \\
\hline $\operatorname{AE}(P A)$ & $34,6^{\mathrm{a}}$ & $35,8^{a}$ & $38,0^{\mathrm{a}}$ & $40,1^{\mathrm{a}}$ & $42,7^{\mathrm{a}}$ & $41,7^{\mathrm{a}}$ & $38,8^{a}$ \\
\hline & & & Lig & $(\%)$ & & & \\
\hline & & & Lig & & & & \\
\hline $\operatorname{MFI}(M W F)$ & $4,1^{\mathrm{a}}$ & $3,9^{\mathrm{a}}$ & $3,6^{\mathrm{a}}$ & $4,0^{\mathrm{a}}$ & $5,2^{\mathrm{a}}$ & $4,4^{\mathrm{a}}$ & $4,2^{\mathrm{a}}$ \\
\hline $\operatorname{AE}(P A)$ & $4,3^{\mathrm{a}}$ & $3,8^{\mathrm{a}}$ & $3,7^{\mathrm{a}}$ & $3,8^{\mathrm{a}}$ & $5,0^{\mathrm{a}}$ & $4,5^{\mathrm{a}}$ & $4,2^{\mathrm{a}}$ \\
\hline
\end{tabular}


Tabela 7 - Teores de fibra em detergente neutro, fibra em detergente ácido e lignina dos componentes forrageiros em pastagens de capim-aruana exclusivo (AE) e capim-aruana sobre-semeado com uma mistura de espécies forrageiras de inverno (MFI) antes da entrada dos ovinos, em seis períodos de pastejo (P), no segundo ano de experimento

Table 7 - Contents of neutral detergent fiber, acid detergent fiber and lignin of the pre-grazing botanical composition in pure aruanagrass (PA) and aruanagrass oversown with a mixture of winter forages (MWF), in the six grazing periods of the second year

\begin{tabular}{|c|c|c|c|c|c|c|c|}
\hline \multirow[b]{2}{*}{$\begin{array}{l}\text { Componente forrageiro } \\
\text { Botanical component }\end{array}$} & \multicolumn{6}{|c|}{$\begin{array}{l}\text { Período de pastejo } \\
\text { Grazing period }\end{array}$} & \multirow[b]{2}{*}{$\begin{array}{l}\text { Média* } \\
\text { Mean* }\end{array}$} \\
\hline & $\begin{array}{c}\mathrm{P} 1 \\
27 / 07 \mathrm{a} \\
06 / 08 / 01 \\
07-27 \text { to } \\
08-06-01\end{array}$ & $\begin{array}{c}\mathrm{P} 2 \\
06 / 09 \mathrm{a} \\
16 / 09 / 01 \\
09-06 \text { to } \\
09-16-01\end{array}$ & $\begin{array}{c}\mathrm{P} 3 \\
22 / 10 \mathrm{a} \\
02 / 11 / 01 \\
10-22 \text { to } \\
11-02-01\end{array}$ & $\begin{array}{c}\mathrm{P} 4 \\
26 / 11 \mathrm{a} \\
11 / 12 / 01 \\
11-26 \text { to } \\
12-11-01\end{array}$ & $\begin{array}{c}\mathrm{P} 5 \\
02 / 01 \text { a } \\
14 / 01 / 02 \\
01-02 \text { to } \\
01-14-02\end{array}$ & $\begin{array}{c}\mathrm{P} 6 \\
06 / 02 \mathrm{a} \\
22 / 02 / 02 \\
02-06 \text { to } \\
02-22-02\end{array}$ & \\
\hline \multicolumn{8}{|c|}{$\begin{array}{l}\text { Fibra em detergente neutro }(\%) \\
\quad \text { Neutral detergent fiber }(\%)\end{array}$} \\
\hline $\begin{array}{l}\text { Aruana }(\mathrm{AE}) \\
\text { Aruanagrass }(P A)\end{array}$ & $70,3^{\mathrm{a}}$ & $70,5^{\mathrm{a}}$ & $72,8^{\mathrm{a}}$ & $77,1^{\mathrm{a}}$ & $74,3^{\mathrm{a}}$ & $76,4^{\mathrm{a}}$ & $73,6^{\mathrm{a}}$ \\
\hline $\begin{array}{l}\text { Aruana (MFI) } \\
\text { Aruanagrass }(M W F)\end{array}$ & $69,3^{\mathrm{a}}$ & $69,4^{\mathrm{a}}$ & $70,8^{\mathrm{a}}$ & $74,1^{\mathrm{a}}$ & $73,9^{\mathrm{a}}$ & $75,4^{\mathrm{a}}$ & $72,1^{\mathrm{a}}$ \\
\hline $\begin{array}{l}\text { Aveia (MFI) } \\
\text { Oat }(M W F)\end{array}$ & $56,2^{\mathrm{B}}$ & $63,9^{\mathrm{A}}$ & - & - & - & - & 60,8 \\
\hline $\begin{array}{l}\text { Azevém (MFI) } \\
\text { Ryegrass }(M W F)\end{array}$ & $51,7^{\mathrm{B}}$ & $55,6^{\mathrm{B}}$ & $73,6^{\mathrm{A}}$ & - & - & - & 61,5 \\
\hline \multicolumn{8}{|c|}{$\begin{array}{c}\text { Fibra em detergente ácido (\%) } \\
\text { Acid detergent fiber (\%) }\end{array}$} \\
\hline $\begin{array}{l}\text { Aruana (AE) } \\
\text { Aruanagrass (PA) }\end{array}$ & $32,7^{\mathrm{a}}$ & $31,1^{\mathrm{a}}$ & $35,9^{\mathrm{a}}$ & $40,5^{\mathrm{a}}$ & $41,1^{\mathrm{b}}$ & $40,4^{\mathrm{a}}$ & $36,9^{b}$ \\
\hline $\begin{array}{l}\text { Aruana (MFI) } \\
\text { Aruanagrass }(M W F)\end{array}$ & $34,6^{\mathrm{a}}$ & $33,5^{\mathrm{a}}$ & $38,5^{\mathrm{a}}$ & $41,6^{\mathrm{a}}$ & $43,9^{\mathrm{a}}$ & $42,7^{\mathrm{a}}$ & $39,1^{\mathrm{a}}$ \\
\hline $\begin{array}{l}\text { Aveia (MFI) } \\
\text { Oat }(M W F)\end{array}$ & $29,3^{\mathrm{A}}$ & $29,1^{\mathrm{A}}$ & - & - & - & - & 28,4 \\
\hline $\begin{array}{l}\text { Azevém (MFI) } \\
\text { Ryegrass }(M W F)\end{array}$ & $26,9^{\mathrm{B}}$ & $28,7^{\mathrm{B}}$ & $44,4^{\mathrm{A}}$ & - & - & - & 33,6 \\
\hline \multicolumn{8}{|c|}{$\begin{array}{l}\text { Lignina }(\%) \\
\text { Lignin }(\%)\end{array}$} \\
\hline $\begin{array}{l}\text { Aruana }(\mathrm{AE}) \\
\text { Aruanagrass }(P A)\end{array}$ & $3,7^{\mathrm{a}}$ & $3,4^{\mathrm{a}}$ & $3,4^{\mathrm{a}}$ & $3,9^{\mathrm{a}}$ & $4,4^{\mathrm{a}}$ & $4,2^{\mathrm{a}}$ & $3,8^{\mathrm{a}}$ \\
\hline $\begin{array}{l}\text { Aruana (MFI) } \\
\text { Aruanagrass }(M W F)\end{array}$ & $3,8 \mathrm{a}$ & $3,6 a$ & $3,4 a$ & $3,7 \mathrm{a}$ & $4,7 \mathrm{a}$ & $3,7 \mathrm{a}$ & $3,8 \mathrm{a}$ \\
\hline $\begin{array}{l}\text { Aveia (MFI) } \\
\text { Oat }(M W F)\end{array}$ & $2,5^{\mathrm{B}}$ & $3,2^{\mathrm{A}}$ & - & - & - & - & 2,9 \\
\hline $\begin{array}{l}\text { Azevém (MFI) } \\
\text { Ryegrass }(M W F)\end{array}$ & $2,2^{\mathrm{C}}$ & $3,1^{\mathrm{B}}$ & $4,1^{\mathrm{A}}$ & - & - & - & 3,9 \\
\hline
\end{tabular}

* EPM: erro-padrão da média (standard error of mean).

$\mathrm{EPM}_{\mathrm{MFI}, \mathrm{AE}-\mathrm{FDN}(\text { Aruana) }}=0,4842 ; \mathrm{EPM}_{\mathrm{MFI-FDN}(\text { Aveia })}=0,5613 ; \mathrm{EPM}_{\mathrm{MFI-FDN}(\text { Azevém) }}=0,8991 ; \mathrm{EPM}_{\mathrm{MFI}-\mathrm{FDA}(\text { Aruana) }}=0,4700 ; \mathrm{EPM}_{\mathrm{AE}-}$

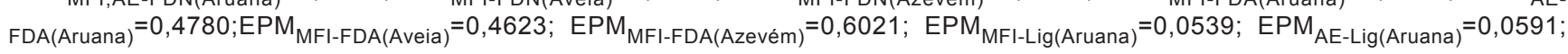

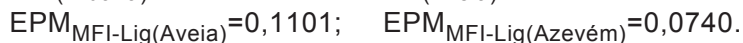

ab Médias seguidas de mesmas letras minúsculas, nas colunas, para cada variável, não diferem entre si $(P>0,10)$.

$A B$ Médias seguidas de mesmas letras maiúsculas, nas linhas, não diferem entre si $(P>0,10)$.

ab Means followed by the same small letters, in the columns, for each variable, do not differ $(P>0.10)$.

${ }_{A B}$ Means followed by the same capital letters, in the rows, do not differ $(P>0.10)$.

traram queda no valor nutritivo das forrageiras com o avanço nos períodos de pastejo.

Os valores da DIVMS da massa total de forragem dos componentes forrageiros encontram-se na Tabela 8. Não houve diferença $(P=0,4333)$ entre os tipos de pastagens quando se avaliou a digestibilidade da forragem oferecida aos animais, ao longo dos períodos de pastejo.
Para a DIVMS do componente aruana (Tabela 8), na média dos seis períodos, não houve diferença significativa $(P=0,5368)$ entre a pastagem de capimaruana sobre-semeada e a exclusiva, obtendo-se valores que podem ser considerados elevados, de 71,3 e $71,0 \%$, respectivamente, para a pastagem de capim-aruana com MFI e de AE. 
Tabela 8 - Digestibilidade in vitro da matéria seca da massa total de forragem e dos seus componentes forrageiros em pastagens de capim-aruana exclusivo (AE) e capim-aruana sobre-semeado com uma mistura de espécies forrageiras de inverno (MFI) antes da entrada dos ovinos, em seis períodos de pastejo $(\mathrm{P})$, no segundo ano de experimento

Table 8 - In vitro dry matter digestibility of pre-grazing forage mass and botanical composition in pure aruanagrass (PA) and aruanagrass oversown with a mixture of winter forages (MWF), in the six grazing periods of the second year

\begin{tabular}{|c|c|c|c|c|c|c|c|}
\hline \multirow{6}{*}{$\begin{array}{l}\text { Tipo de pastagem } \\
\text { Pastures type }\end{array}$} & \multicolumn{6}{|c|}{$\begin{array}{l}\text { Período de pastejo } \\
\text { Grazing period }\end{array}$} & \multirow{6}{*}{$\begin{array}{l}\text { Média* } \\
\text { Mean* }\end{array}$} \\
\hline & P1 & $\mathrm{P} 2$ & P3 & P4 & P5 & P6 & \\
\hline & $27 / 07 a$ & $06 / 09 a$ & $22 / 10 a$ & $26 / 11 \mathrm{a}$ & $02 / 01 \mathrm{a}$ & $06 / 02 \mathrm{a}$ & \\
\hline & $06 / 08 / 01$ & $16 / 09 / 01$ & $02 / 11 / 01$ & $11 / 12 / 01$ & $14 / 01 / 02$ & $22 / 02 / 02$ & \\
\hline & $07-27$ to & 09-06 to & $10-22$ to & $11-26$ to & $01-02$ to & $02-06$ to & \\
\hline & $08-06-01$ & $09-16-01$ & $11-02-01$ & $12-11-01$ & $01-14-02$ & $02-22-02$ & \\
\hline \multicolumn{8}{|c|}{ Total $(\%)$} \\
\hline \multicolumn{8}{|c|}{ Total (\%) } \\
\hline $\operatorname{MFI}(M W F)$ & $72,4^{\mathrm{a}}$ & $72,2^{\mathrm{a}}$ & $69,1^{\mathrm{a}}$ & $69,9^{\mathrm{a}}$ & $65,1^{\mathrm{a}}$ & $59,8^{\mathrm{a}}$ & $68,1^{\mathrm{a}}$ \\
\hline $\operatorname{AE}(P A)$ & $70,2^{\mathrm{a}}$ & $71,7^{\mathrm{a}}$ & $70,0^{\mathrm{a}}$ & $71,6^{\mathrm{a}}$ & $66,2^{\mathrm{a}}$ & $62,3^{\mathrm{a}}$ & $68,6^{\mathrm{a}}$ \\
\hline \multicolumn{8}{|c|}{ Aruana (\%) } \\
\hline \multicolumn{8}{|c|}{ Aruanagrass (\%) } \\
\hline $\operatorname{MFI}(M W F)$ & $73,6^{\mathrm{a}}$ & $74,5^{\mathrm{a}}$ & $70,7^{\mathrm{a}}$ & $73,2^{\mathrm{a}}$ & $69,2^{\mathrm{a}}$ & $66,4^{\mathrm{a}}$ & $71,3^{\mathrm{a}}$ \\
\hline $\mathrm{AE}(P A)$ & $74,0^{\mathrm{a}}$ & $75,4^{\mathrm{a}}$ & $70,3^{\mathrm{a}}$ & $70,2^{\mathrm{a}}$ & $70,0^{\mathrm{a}}$ & $66,1^{\mathrm{a}}$ & $71,0^{\mathrm{a}}$ \\
\hline \multicolumn{8}{|c|}{ Aveia preta (\%) } \\
\hline \multicolumn{8}{|c|}{ Black oat (\%) } \\
\hline \multirow{2}{*}{\multicolumn{8}{|c|}{$\begin{array}{c}\text { Azevém }(\%) \\
\text { Italian ryegrass (\%) }\end{array}$}} \\
\hline & & & & rass $(\%)$ & & & \\
\hline $\operatorname{MFI}(M W F)$ & $76,4^{\mathrm{A}}$ & $77,4^{\mathrm{A}}$ & $68,2^{\mathrm{B}}$ & - & - & - & 74,0 \\
\hline
\end{tabular}

* EPM: erro-padrão da média (standard error of mean). $\mathrm{EPM}_{\mathrm{MFI}-\mathrm{Total}}=0,6421 ; \mathrm{EPM}_{\mathrm{AE}-\mathrm{Total}}=0,6413 ; \mathrm{EPM}_{\mathrm{MFI}-\mathrm{Aruana}}=0,4254 ; \mathrm{EPM}_{\mathrm{AE}-\mathrm{Aruana}}=$ 0,4262; EPM $_{\text {MFI-Aveia }}=0,2098 ;$ EPM $_{\text {MFI-Azevém }}=0,6736$

ab Médias seguidas de mesmas letras minúsculas, nas colunas, para cada variável, não diferem entre si $(P>0,10)$.

$A B$ Médias seguidas de mesmas letras maiúsculas, nas linhas, não diferem entre si $(P>0,10)$.

ab Means followed by the same small letters, in the columns, for each variable, do not differ $(P>0.10)$.

$A B$ Means followed by the same capital letters, in the rows, do not differ $(P>0.10)$.

A aveia preta apresentou os melhores resultados de PB e constituintes da parede celular (Tabelas 5 e 7) na avaliação inicial (P1), quando a espécie se encontrava em pleno estádio de crescimento vegetativo, em relação à avaliação seguinte(P2), quando a aveia finalizou seu ciclo. Entretanto, analisando-se a digestibilidade deste componente (Tabela 8), verificam-se valores semelhantes $(P=0,7239)$ desta variávelentre os dois períodos de pastejo, contrariando as expectativas baseadas nos teores de PB e fibras e discordando dos resultados obtidos por Lupatini et al. (1998), Roso et al. (1999) e Restle et al. (2000).

Os valores de DIVMS do azevém (Tabela 8) mantiveram-se constantes nos primeiros dois períodos de pastejo, que foram maiores que o último, no qual ocorreu redução acentuada, em razão dos maiores valores de FDN, FDA e lignina (Tabela 7) e do menor teor de proteína bruta (Tabela 5).

\section{Conclusões}

Ocorre acentuada redução no valor nutritivo das espécies forrageiras de inverno, ao longo do período de utilização.

Na maioria dos períodos de pastejo, os teores de FDN, FDA e lignina nas pastagens de capimaruana exclusivo e naquelas contendo a mistura de aveia preta e azevém são semelhantes. As digestibilidades da forragem ofertada, nos dois tipos de pastagem, também foram semelhantes em todos os períodos de pastejo.

Pastos de capim-aruana, com adubação nitrogenada, irrigação e manejo adequados, apresentam composição química e digestibilidade semelhantes às de pastos do capim sobre-semeados com aveia preta e azevém. 


\section{Agradecimento}

À Fundação de Amparo à Pesquisa do Estado de São Paulo (FAPESP), pela bolsa de doutorado concedida à autora principal, para a execução do projeto, e ao Instituto de Zootecnia de Nova Odessa, SP, pela infra-estrutura e pela oportunidade concedida para a realização deste trabalho.

\section{Literatura Citada}

ASSOCIATION OF OFFICIAL ANALYTICAL CHEMISTS AOAC. Micro Kjeldahl method. In: CUNNIFF, P. (Ed.). Official methods of analysis of AOAC International. Arlington: 1995. p.7.

BLASER, R.E. Symposium on forage utilization: effects of fertility levels and stage of maturity on forage nutritive value. Journal of Animal Science, v.23, p.246-253, 1964.

CECATO, U.; FAVORETTO, V.; MALHEIROS, E.B. Freqüências de corte, níveis e formas de aplicação de nitrogênio sobre a composição bromatológica de capim-Aruana (Panicum maximum Jacq. cv Aruana). Revista UNIMAR, v.16, n.3, p.277-291, 1994.

EUCLIDES, V.P.B.; MACEDO, M.C.M; ZIMMER, A.H. et al. Valores nutritivos de cinco gramíneas sob pastejo. In: REUNIÃO DA SOCIEDADE BRASILEIRA DE ZOOTECNIA, 33., Fortaleza, 1996. Anais... Fortaleza: Sociedade Brasileira de Zootecnia, 1996. p.90-92.

FLOSS, E.L. Manejo forrageiro de aveia (Avena sp.) e azevém (Lolium SP). In: SIMPÓSIO SOBRE MANEJO DA PASTAGEM, 9., 1988, Piracicaba. Anais... Piracicaba: Fundação de Estudos Agrários Luiz de Queiroz, 1988. p.231-268.

GERDES, L.; MATTOS, H.B.; WERNER, J.C. et al. Características do dossel forrageiro e acúmulo de forragem em pastagem irrigada de capim-aruana exclusivo ou sobre-semeado com uma mistura de espécies forrageiras de inverno. Revista Brasileira de Zootecnia, v.34, n.4, p.1088-1097, 2005.

GHISI, O.M.A.; ALMEIDA, A.R.P.; ALCÂNTARA, V.B.G. Avaliação agronômica de seis cultivares de Panicum maximum Jacq. sob três níveis de adubação. Boletim de Indústria Animal, v.46, n.1, p.1-15, 1989.

GOERING, N.K.; Van SOEST, P.J. Forage fiber analysis: apparatus, reagents, procedures and some application. Washinghton, 1970. 20p. (USDA. Agriculture Handbook).
GOMES, J.F.; REIS, J.C.L. Produção de forrageiras anuais de estação fria no litoral sul do Rio Grande do Sul. Revista Brasileira de Zootecnia, v.28, n.4, p.668-674, 1999.

LITTELL, R.C.; MILLIKEN, G.A.; STROUP, W.W. et al. SAS ${ }^{\circledR}$ system for mixed models. Cary: 1996. 633p.

LUPATINI, G.C., RESTLE, J.; CERETTA, M. et al. Avaliação da mistura de aveia preta (Avena strigosa) e azevém (Lolium multiflorum ) sob pastejo submetida a níveis de nitrogênio. I-Produção e qualidade de forragem. Pesquisa Agropecuária Brasileira, v.23, n.11, p.1939-1943, 1998.

REIS, R.A.; RODRIGUES, L.R.A.; COAN, O. et al. Produção e qualidade da forragem de aveia (Avena spp.). Revista Brasileira de Zootecnia, v.22, n.1, p.99-109, 1993.

REIS, R.A.; SOLLENBERGER, L.E.; URBANO, D. Impact of overseeding cool-season annual forages on spring regrowth of Tifton 85 bermudagrass. In: INTERNATIONAL GRASSLAND CONGRESS, 19., São Pedro, 2001. Proceedings... São Pedro: Brazilian Society of Animal Husbandry, 2001. p.295-297.

RESTLE, J; ROSO, C.; SOARES, A.B. et al. Produtividade animal e retorno econômico em pastagem de aveia preta mais azevém adubada com fontes de nitrogênio em cobertura. Revista Brasileira de Zootecnia, v.29, n.2, p.357-364, 2000.

ROSO, C., RESTLE, J., SOARES, A.B. et al. Produção e qualidade de forragem da mistura de gramíneas anuais de estação fria sob pastejo contínuo. Revista Brasileira de Zootecnia, v.28, n.3, p.459-467, 1999.

STATISTICAL ANALYSES SYSTEM - SAS. SAS/STAT: user's guide, versão 6,4. Cary: 1990. 846p.

SILVA, D.J. Análise de alimentos: métodos químicos e biológicos. Viçosa, MG: Universidade Federal de Viçosa, 1981. 165p.

TILLEY, J.M.A.; TERRY, R.A. A two-stage technique for the "in vitro" digestion of forage crops. Journal of the British Grassland Society, v.18, n.2, p.104-111, 1963.

Van SOEST, P.J. Nutritional ecology of the ruminant. Corvalis: Cornell University, 1982. 374p.

ZIMMER, A.H. Efeito de níveis de nitrogênio e de resíduos pós-pastejo sobre a produção, a estrutura e a qualidade das cultivares Aruana e Vencedor de Panicum maximum. Jaboticabal: Universidade Estadual Paulista, 1999. 213p. Tese (Doutorado) - Universidade Estadual Paulista, 1999.

Recebido em: 06/08/03 Aceito em: 29/10/04 